OPEN ACCESS

Edited by:

Lan Li,

Nanjing Drum Tower Hospital, China

Reviewed by: Jie Chen,

National University of Singapore,

Singapore

Fupo He,

Guangdong University of Technology,

China

Yang Zheng,

Tianjin Polytechnic University, China

*Correspondence:

Zhigang Liu

9120030053@jxust.edu.cn

Cijun Shuai

shuai@csu.edu.cn

shuai@jxust.edu.cn

Specialty section:

This article was submitted to

Biomaterials,

a section of the journal Frontiers in Bioengineering and

Biotechnology

Received: 27 September 2021

Accepted: 22 October 2021

Published: 02 December 2021

Citation:

Yang Y, Cai G, Yang M, Wang D,

Peng S, Liu Z and Shuai C (2021) Laser

Additively Manufactured Iron-Based

Biocomposite: Microstructure,

Degradation, and In Vitro Cell Behavior.

Front. Bioeng. Biotechnol. 9:783821.

doi: 10.3389/fbioe.2021.783821

\section{Laser Additively Manufactured Iron-Based Biocomposite: Microstructure, Degradation, and In Vitro Cell Behavior}

\author{
Youwen Yang ${ }^{1}$, Guoqing Cai ${ }^{1}$, Mingli Yang ${ }^{1}$, Dongsheng Wang ${ }^{2}$, Shuping Peng ${ }^{3,4}$, \\ Zhigang Liu ${ }^{5 *}$ and Cijun Shuai ${ }^{1,6 *}$
}

${ }^{1}$ Institute of Additive Manufacturing, Jiangxi University of Science and Technology, Nanchang, China, ${ }^{2}$ Key Laboratory of Construction Hydraulic Robots of Anhui Higher Education Institutes, Tongling University, Tongling, China, ${ }^{3}$ School of Energy and Mechanical Engineering, Jiangxi University of Science and Technology, Nanchang, China, ${ }^{4} \mathrm{NHC}$ Key Laboratory of

Carcinogenesis, The Key Laboratory of Carcinogenesis and Cancer Invasion of the Chinese Ministry of Education, School of Basic Medical Science, Central South University, Changsha, China, ${ }^{5}$ School of Electrical Engineering and Automation, Jiangxi University of Science and Technology, Ganzhou, China, ${ }^{6}$ State Key Laboratory of High Performance Complex Manufacturing, Central South University, Changsha, China

A too slow degradation of iron (Fe) limits its orthopedic application. In this study, calcium chloride $\left(\mathrm{CaCl}_{2}\right)$ was incorporated into a Fe-based biocomposite fabricated by laser additive manufacturing, with an aim to accelerate the degradation. It was found that $\mathrm{CaCl}_{2}$ with strong water absorptivity improved the hydrophilicity of the Fe matrix and thereby promoted the invasion of corrosive solution. On the other hand, $\mathrm{CaCl}_{2}$ could rapidly dissolve once contacting the solution and release massive chloride ion. Interestingly, the local high concentration of chloride ion effectively destroyed the corrosion product layer due to its strong erosion ability. As a result, the corrosion product layer covered on the $\mathrm{Fe} / \mathrm{CaCl}_{2}$ matrix exhibited an extremely porous structure, thus exhibiting a significantly reduced corrosion resistance. Besides, in vivo cell testing proved that the $\mathrm{Fe} / \mathrm{CaCl}_{2}$ biocomposite also showed favorable cytocompatibility.

Keywords: laser additive manufacturing, iron bone implant, calcium chloride, degradation properties, cell behavior

\section{INTRODUCTION}

In recent years, iron $(\mathrm{Fe})$ has been recognized as a potential bone tissue engineering material owing to its good biocompatibility and mechanical properties (Cheng et al., 2013; Yang et al., 2020a). As compared with the other two biodegradable metals, including magnesium and zinc, Fe possesses relatively high mechanical strength and is more suitable for the repair of loadbearing bone tissue (Li et al., 2018). Fe is an essential micronutrient for the human body and participates in metabolism and various physiological functions, such as hemoglobin synthesis, metabolic enzyme activation, and immunity enhancement (Hermawan et al., 2010; Shuai et al., 2021a). As one kind of biodegradable metal, Fe can be naturally degraded and absorbed in the human body, thus avoiding secondary surgery (Spotorno et al., 2020). However, Fe degrades too slowly, which should hinder the formation and growth of new bone and even cause inflammatory reaction (Yang et al., 2018). The slow degradation is related to the formation of passive film (Sharma and Pandey, 2019). According to the theory of phase-forming film, a dense and wellcovered product film could be formed on the Fe matrix as corrosion occurred (Kim et al., 2019). 

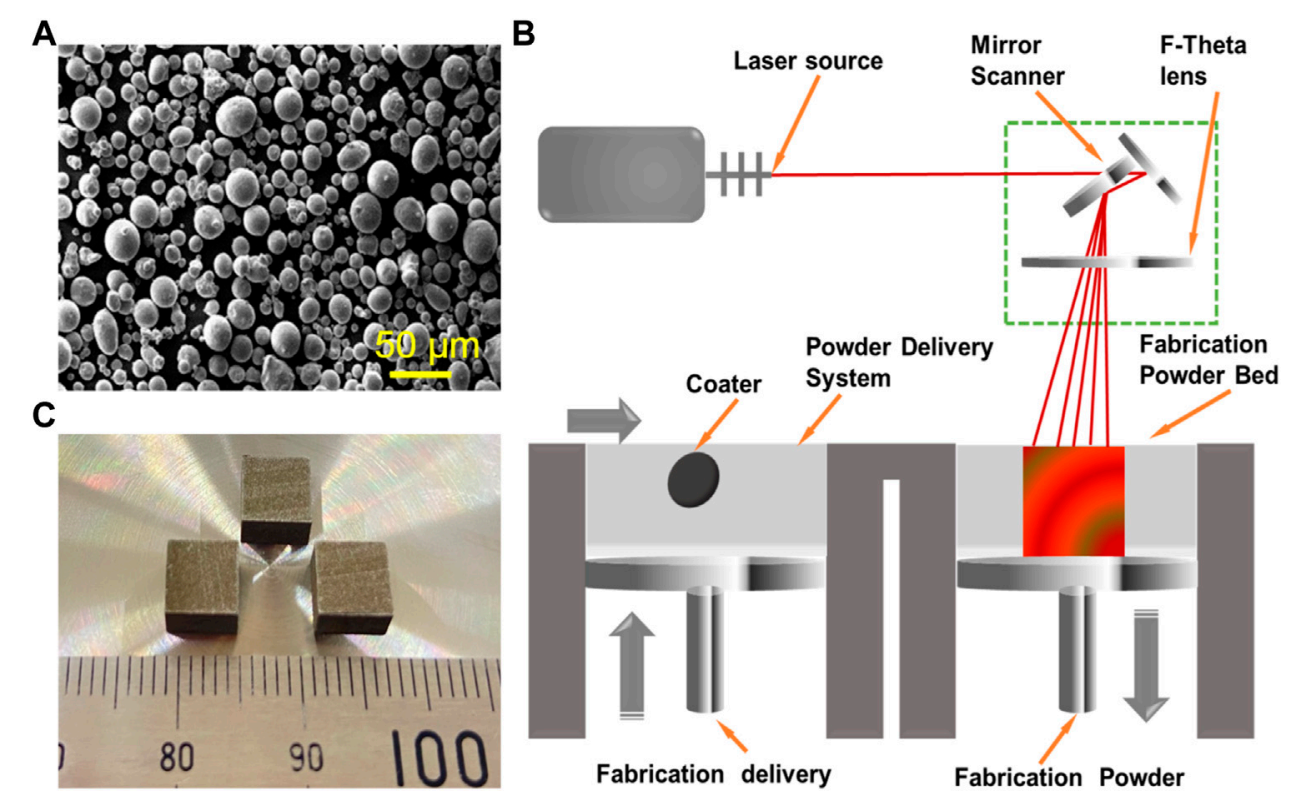

FIGURE 1 | (A) Sphere Fe powders. (B) Schematic diagram of laser additive manufacturing. (C) The as-built parts prepared by LPBF.

The thin film firmly combined with the Fe matrix could be regarded as an independent solid phase (Wang et al., 2020).

Destroying the passive film of a metallic surface by halogen ion breakdown is an effective way to accelerate the degradation (Yin et al., 2020). Halogen ions, such as chlorine, fluorine, and bromine ions, with strong electronegativity could penetrate into the interface between the metallic matrix and the surface film (Liu et al., 2017; Zhang et al., 2018; Gu et al., 2021). In this case, it would generate lattice expansion and resultant tensile stress at the interface, thus destroying the surface passive film. According to the research of Kong et al. (Kong et al., 2018), halogen ion could cause the relaxation of the passive film structure, so as to achieve the effect of breakdown. Wang et al. (Wang et al., 2014) found that halogen ion could change the film passive structure during the formation of the passive film, thus reducing the protective effect and accelerating the matrix corrosion. Zhou et al. (Zhou et al., 2020) also confirmed that halogen ion destroyed the passive film by potentiodynamic polarization.

In this work, calcium chloride $\left(\mathrm{CaCl}_{2}\right)$, as a halide, was incorporated into Fe-based bone implants fabricated by laser powder bed fusion (LPBF). It was expected that $\mathrm{CaCl}_{2}$ would release $\mathrm{Cl}$ ion to accelerate the corrosion by attacking the passive film covered on the Fe matrix. Meanwhile, it could also offer $\mathrm{Ca}$ ion, one nutrient element that could promote cell proliferation and differentiation (Seol et al., 2014; Chen et al., 2020). LPBF, as additive manufacturing technology, was able to easily fabricate bone tissue engineering scaffold with a complicated pore structure and personalized outer shape, thus meeting the application requirement for different patients (Gao et al., 2021a; Shuai et al., 2021b; Yang et al., 2021). Moreover, it utilized high-energy laser beam as a heat source, which could deal with a wide range of material systems, including metals, ceramics, polymers, and their composites (Pérez-Ruiz et al., 2021; Wang et al., 2021). Herein, the microstructure feature, degradation performance, and corrosion behavior for the $\mathrm{Fe} / \mathrm{CaCl}_{2}$ composite were systematically studied. In addition, the biocompatibility was also evaluated synthetically to assess its potential application in bone defect repair.

\section{MATERIAL AND METHODS}

\section{Preparation of the $\mathrm{Fe} / \mathrm{CaCl}_{2}$ Powder}

Sphere Fe powder $(25-50 \mu \mathrm{m})$ and $\mathrm{CaCl}_{2}$ powder $(1-3 \mu \mathrm{m})$ were used as raw materials, as shown in Figure 1A. The mixed powder containing 5 wt. $\%$ of $\mathrm{CaCl}_{2}$ was milled using a miniature planet ball mill (PULVERISETTE 6, Fritsch, Idar-Oberstein, Germany) at room temperature for $2 \mathrm{~h}$. The rotation rate was $200 \mathrm{rpm}$, and the powder-to-ball weight ratio was determined at 1:10. The ball mill was suspended for half an hour every $15 \mathrm{~min}$ to cool down the vial. Before operation, the sealed vial was vacuumed and filled with argon (99.99\% purity) aiming to avoid the oxidation. Lastly, the mixture was dried in a vacuum drying oven for $8 \mathrm{~h}$ at $125^{\circ} \mathrm{C}$.

\section{LPBF of Fe-Based Biocomposite}

The as-milled powder was used for laser additive manufacturing experiments. The manufacturing system consisted of a fiber laser (IPG, $500 \mathrm{~W}$, Germany), a computer control system, and a building chamber filled with purity argon, as displayed in Figure 1B. The optimized process parameters obtained by a series of pre-experiments were as follows: laser power $110 \mathrm{~W}$, scanning rate $12 \mathrm{~mm} / \mathrm{s}$, hatching space $50 \mu \mathrm{m}$, and layer thickness $50 \mu \mathrm{m}$. The laser scanning strategy was set as an alternating scanning strategy, in which the scanning vectors rotated $90^{\circ}$ 
relative to the previous layer. The typical additively manufactured parts are displayed in Figure 1C, and the size was $6 \mathrm{~cm}$ in length, $6 \mathrm{~cm}$ in width, and $6 \mathrm{~cm}$ in height.

\section{Microstructural Characterization}

The as-built parts were grounded to 2,000 mesh utilizing $\mathrm{SiC}$ paper and then polished with diamond paste under the lubrication of ethanol. The microstructure was characterized utilizing a scanning electron microscope (SEM, EVO 18, Zeiss, Oberkochen, Germany) at $20 \mathrm{kV}$. The phase composition was determined utilizing an X-ray diffractometer (XRD, D8 Advance, Karlsruhe, Germany) with $\mathrm{Cu}-\mathrm{K} \alpha$ radiation $(\lambda=0.15406 \mathrm{~nm})$ at $40 \mathrm{kV}$ and $40 \mathrm{~mA}$. The scanning range was set at $10^{\circ}-90^{\circ}$. The texture was investigated using an electron backscattering diffractometer (EBSD, Symmetry, Oxford Instruments, Abingdon, UK), in which the accelerating voltage varied within $12-30 \mathrm{kV}$ by steps of $0.1 \mathrm{kV}$ in a maximum depth range of $4-5 \mu \mathrm{m}$. Before EBSD analysis, the samples were prepared by electropolishing in an ethanol solution containing 12 vol.\% of water and 8 vol.\% of perchloric acid. The surface hydrophilic angles were measured utilizing a contact angle measurement instrument (Shanghai Zhongchen Technology Apparatus Co., Ltd., Shanghai, China) with a $3 \mathrm{ml}$ distilled water droplet suspended from the tip of the microliter syringe.

\section{Immersion Tests}

Immersion tests were implemented to investigate the corrosion behavior. The samples were immersed in self-prepared simulated body fluid (SBF) for 7, 14, and 28 days. SBF mainly contained $142.0 \mathrm{mM}$ of $\mathrm{Na}^{+}, 5.0 \mathrm{mM}$ of $\mathrm{K}^{+}, 1.5 \mathrm{mM}$ of $\mathrm{Mg}^{2+}, 2.5 \mathrm{mM}$ of $\mathrm{Ca}^{2+}, 125.0 \mathrm{mM}$ of $\mathrm{Cl}^{-}, 327.0 \mathrm{mM}$ of $\mathrm{HCO}^{-}, 41.0 \mathrm{mM}^{-} \mathrm{HPO}^{2-}$, and $40.5 \mathrm{mM}$ of $\mathrm{SO}^{2-}$. After immersion, the samples were washed with distilled water. The corrosion surface was analyzed using SEM. The corrosion product after immersion for 28 days was analyzed utilizing an X-ray photoelectron spectroscope (XPS) with a monochromatic $\mathrm{Al} \mathrm{Ka}$ radiation. High-resolution spectra were recorded at the pass energy of $12.5 \mathrm{eV}$ with an energy step of $0.1 \mathrm{eV}$. The film was deeply analyzed by sputtering of argon ion beam with an energy level of $3 \mathrm{keV}$ and a raster of $2 \times 2 \mathrm{~mm}^{2}$. The sputtering rate was $0.2 \mathrm{~nm} / \mathrm{s}$ determined on $\mathrm{SiO}_{2}$ standard. The samples after immersion 28 days were treated with $200 \mathrm{~g} / \mathrm{L}$ of $\mathrm{CrO}_{3}$ solution to remove the corrosion product. The weight loss was recorded to determine the degradation rate. Besides, the three-dimensional surface morphology was analyzed using an atomic force microscope (AFM, Verco Instruments, USA).

\section{Electrochemical Experiments}

Electrochemical tests were performed using an electrochemical analyzer (PAR model 4,000, Princeton, Oak Ridge, TN, USA) in $\mathrm{SBF}$. The three-electrode battery device was composed of platinum as counterelectrode, saturated calomel as reference electrode, and the testing sample as working electrode. The initial open-loop circuit tests were implemented for $1,800 \mathrm{~s}$ to achieve the voltage stability. Tafel polarization curves were obtained at a scanning rate of $1 \mathrm{mV} / \mathrm{s}$. Electrochemical impedance spectroscopy (EIS) curves for samples with different immersing time were measured at a sinusoidal amplitude of $10 \mathrm{mV}$ with the frequency range of $1,000 \mathrm{kHz}$ to $0.01 \mathrm{~Hz}$. The obtained EIS curves were analyzed by ZSimpWin software. The transient time-current curves were measured from $-2,000$ to $-1,000 \mathrm{mV} / \mathrm{s}$ at a rate of $1 \mathrm{mV} / \mathrm{s}$. The Mott-Schottky curves were determined at a frequency of $1 \mathrm{kHz}$ to evaluate the semiconductor performance of the passive film.

\section{In Vitro Cell Tests}

Cell cytotoxicity was assessed using MG-63 cells (American Type Culture Collection, Rockville, MD, USA). Dulbecco's modified Eagle's medium (DMEM) containing 10\% fetal bovine serum, 100 units $/ \mathrm{ml}$ penicillin, and $100 \mathrm{mg} / \mathrm{ml}$ streptomycin was applied as culture medium. MG-63 cells were cultured in a 96-well plate containing culture medium for 1 day. Before the experiments, the samples were sterilized using ultraviolet light for $30 \mathrm{~min}$ and then immersed in culture medium for 3 days to obtain the extracts. Subsequently, the culture medium was replaced by extracts. After culture for 1, 3, and 5 days, the Calcein AM reagent was used to stain the cells for $15 \mathrm{~min}$. The stained cells were observed utilizing a fluorescence microscope (BX60, Olympus, Tokyo, Japan). Besides, Cell Counting Kit-8 (CCK-8) testing was carried out to assess the cell cytotoxicity. At 1, 3, and 5 days, $10 \mu \mathrm{l}$ of CCK- 8 reagent was dropped into each well and further incubated for $3 \mathrm{~h}$. The absorbance was measured using a microplate reader at $450 \mathrm{~nm}$. Meanwhile, alkaline phosphatase (ALP) staining was carried out to evaluate the differentiation ability of cells cultured for 1 week. After staining, the cells were visualized using a microscope (TE 2000U, Nikon, Tokyo, Japan).

\section{Statistical Analysis}

In the present study, the hydrophilic angle test, immersion tests, electrochemical experiments, and cell tests were carried out at least three times for the averages. SPSS software was used to perform the statistical analysis, in which $p<0.05$ was recognized to be of statistical difference.

\section{RESULTS}

\section{Microstructure of Additively Manufactured Biocomposite}

The microstructure of the $\mathrm{Fe}$ and $\mathrm{Fe} / \mathrm{CaCl}_{2}$ biocomposite after etching is shown in Figure 2A, which clearly revealed the uniform dispersion of $\mathrm{CaCl}_{2}$ in the Fe matrix. EBSD mapping further indicated that the $\mathrm{Fe} / \mathrm{CaCl}_{2}$ composite consisted of refined grains as compared with the Fe part. It was believed that the doped $\mathrm{CaCl}_{2}$ pinned at the grain boundary during LPBF and interrupted the crystal growth. The corresponding XRD spectrum of the as-built parts is shown in Figure 2B. A strong peak corresponding to Fe (110) was clearly observed in two samples, whereas a relatively broadened peak corresponding to $\mathrm{CaCl}_{2}$ (011) presented in the $\mathrm{Fe} / \mathrm{CaCl}_{2}$ composite. The hydrophilicity of the $\mathrm{Fe}$ and $\mathrm{Fe} / \mathrm{CaCl}_{2}$ composite was studied using contact angle measurement. As shown in Figure 2C, the water contact angle gradually decreased with contacting time increasing. Encouragingly, the $\mathrm{Fe} / \mathrm{CaCl}_{2}$ composite showed a significantly decreased 


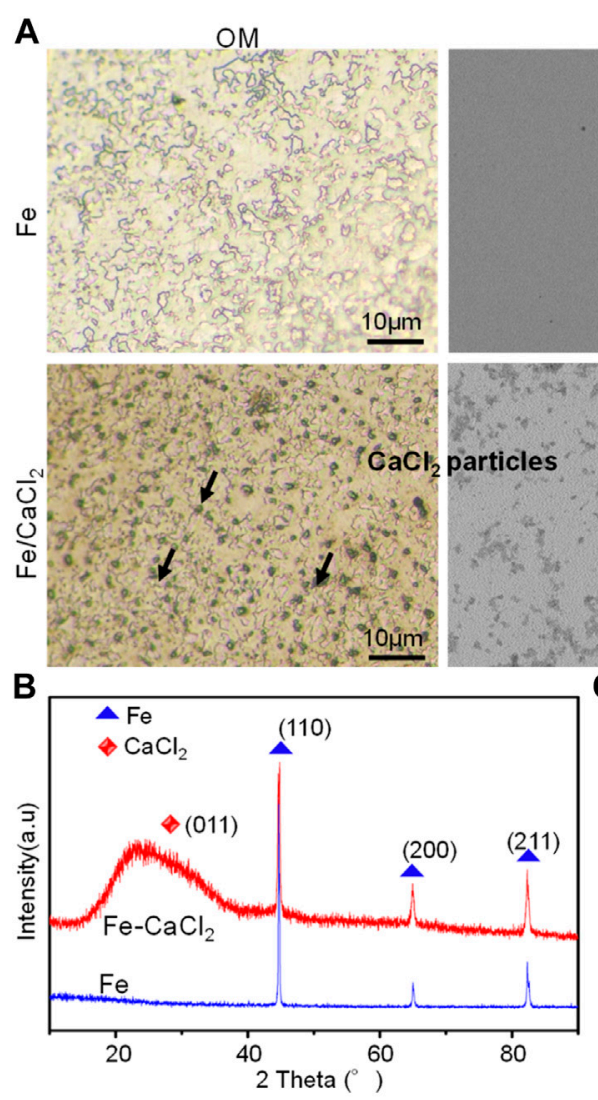

\section{SEM} EBSD

$10 \mu \mathrm{m}$
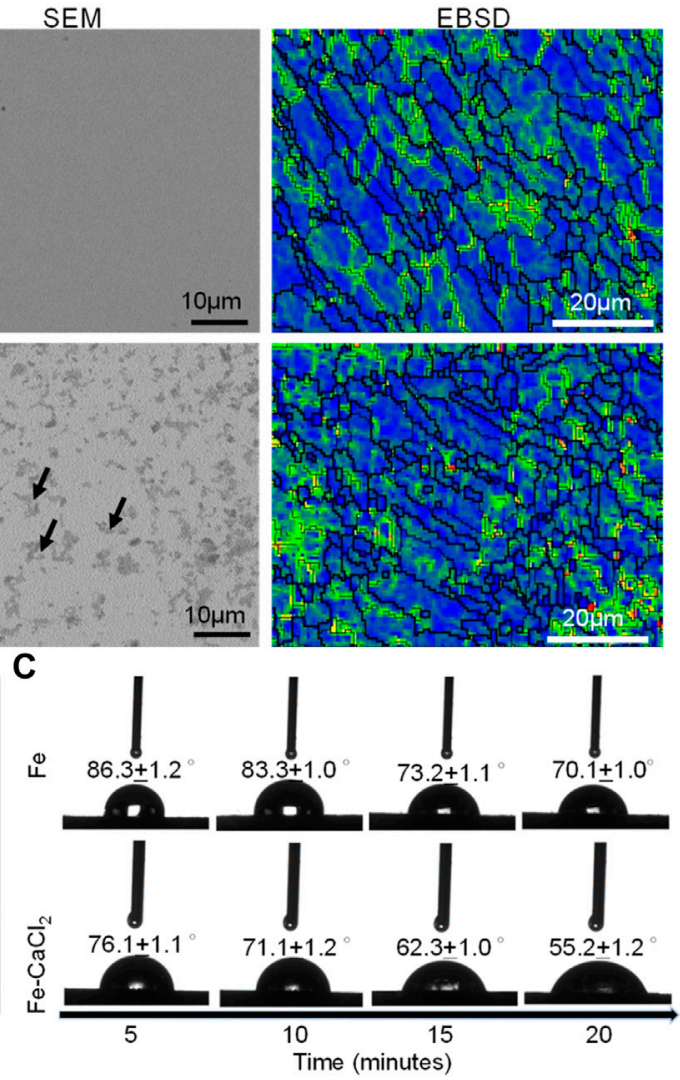

FIGURE 2 | (A) The microstructure, (B) the XRD spectrum, and (C) dynamic results of the hydrophilic angle test.

water contact angle of $55.2 \pm 1.2^{\circ}$, as compared with the Fe part of $70.1 \pm 1.0^{\circ}$. It was directly proved that the incorporation of $\mathrm{CaCl}_{2}$ improved the surface hydrophilicity, which should be conducive to cell adhesion for the Fe-based biocomposite after implantation (Chen et al., 2018).

\section{Degradation Behavior in SBF}

The degradation behavior of the $\mathrm{Fe}$ and $\mathrm{Fe} / \mathrm{CaCl}_{2}$ biocomposites was evaluated by the SBF immersion test. As shown in Figure 3A, the soaking liquid turned yellow turbid with immersion period gradually extending to 28 days, especially for the $\mathrm{Fe} / \mathrm{CaCl}_{2}$ composite. This was mainly attributed to the release of $\mathrm{Fe}^{3+}$ ion caused by the degradation of the $\mathrm{Fe}$ matrix. The corresponding weight losses are displayed in Figure 3B. After immersion for 28 days, the weight loss rates for $\mathrm{Fe}$ and $\mathrm{Fe}-\mathrm{CaCl}_{2}$ were $\sim 0.05$ and $0.18 \mathrm{mg} / \mathrm{cm}^{2} /$ year, respectively. Additionally, the corrosion surface was observed by SEM, as shown in Figure 3C. The flat corrosion surface with few corrosion products was observed for the $\mathrm{Fe}$ part during the whole period. Distinctively, the heavy corrosion product covered on the surface of the $\mathrm{Fe} / \mathrm{CaCl}_{2}$ composite. It should be noted that the corrosion product layer was characterized with a loosened structure and a lot of corrosion pits on it. These pits obviously became deepened and expanded with immersion time extending. As presented in Figure 3C, an enlarged view of SEM clearly proved the porous structure of the corrosion film for $\mathrm{Fe}-\mathrm{CaCl}_{2}$ after 28 days' immersion.

The cross section of corrosion production covered on the $\mathrm{Fe}$ and $\mathrm{Fe} / \mathrm{CaCl}_{2}$ composites after immersion for 28 days is shown in Figure 4A. A uniform corrosion product film with a thickness of $\sim 9.1 \mu \mathrm{m}$ was observed for the $\mathrm{Fe}$ part. For the $\mathrm{Fe} / \mathrm{CaCl}_{2}$ composite, the thickness of the corrosion film increased to $\sim 43.2 \mu \mathrm{m}$. The element mapping results showed that the corrosion product was mainly composed of $\mathrm{Fe}$ and $\mathrm{O}$ elements, which was also confirmed by XPS analysis. According to the scanning spectrum, the corresponding highresolution $\mathrm{Fe}$ and $\mathrm{O}$ spectra were obtained. Spin-orbit peaks of $\mathrm{Fe} 2 \mathrm{p}_{3 / 2}$ and $2 \mathrm{p}_{1 / 2}$ in the high-resolution Fe spectra are located at 711.4 and $724.6 \mathrm{eV}$, both of which corresponded to $\mathrm{Fe}_{2} \mathrm{O}_{3}$ as the main corrosion product. The $\mathrm{O} 1 \mathrm{~s}$ spectrum of the $\mathrm{Fe} / \mathrm{CaCl}_{2}$ composite in the high-resolution $\mathrm{O}$ spectra had two new bands as compared with that of Fe. The peaks of the two bands were located at 531.0 and $529.4 \mathrm{eV}$, respectively, which were assigned to lattice oxygen and metal oxygen (Wu et al., 2020; Zhou et al., 2020).

The surface topography of the $\mathrm{Fe}$ and $\mathrm{Fe} / \mathrm{CaCl}_{2}$ composites with the corrosion product removed was analyzed by AFM, as shown in Figure 5. The surface of the Fe matrix showed only a few of small and shallow corrosion pits. In contrast, massive deep and large corrosion pits presented on the $\mathrm{Fe} / \mathrm{CaCl}_{2}$ 


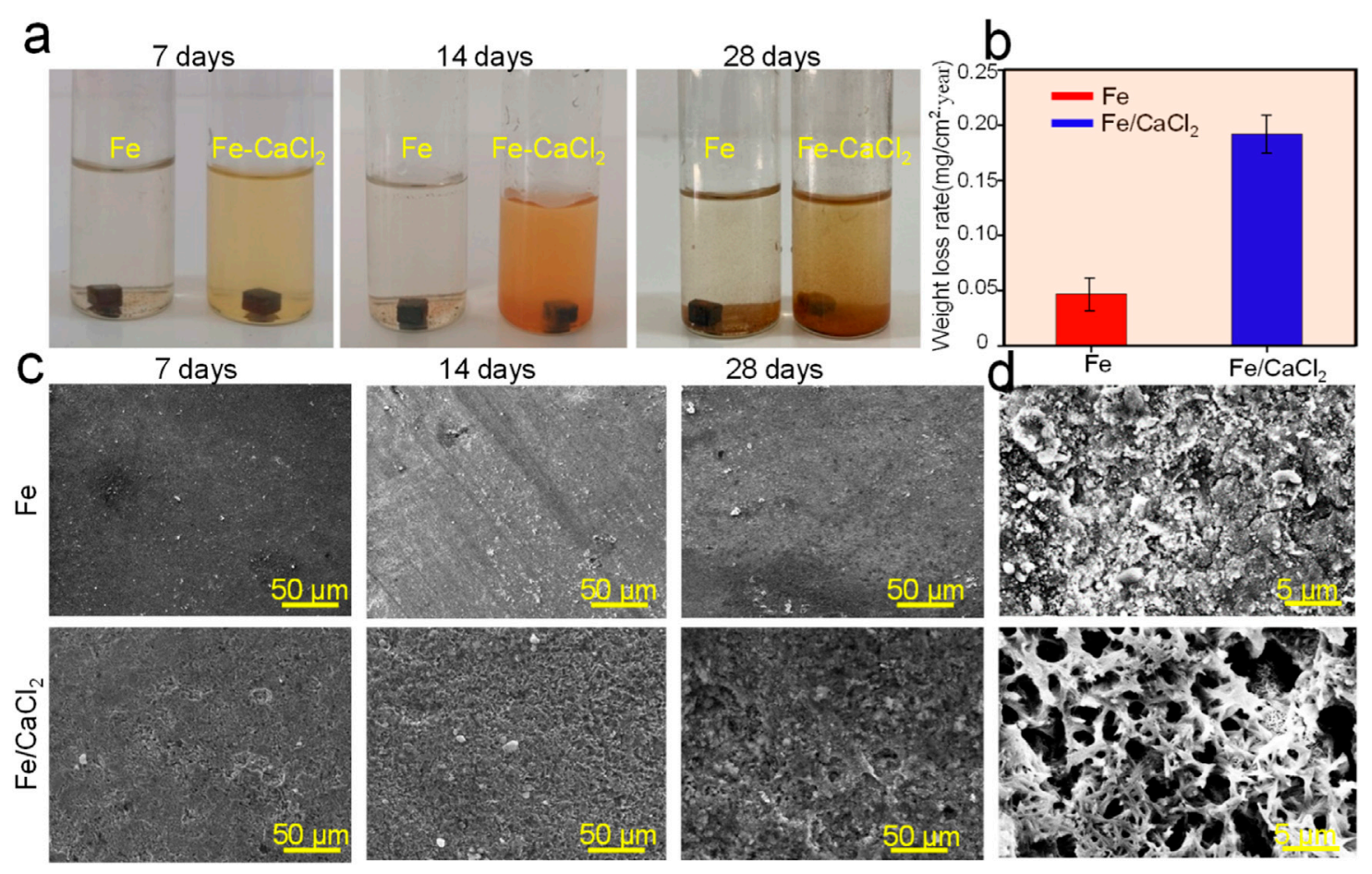

FIGURE 3 | (A) The photograph showing the samples immersed in SBF for 7, 14, and 28 days, (B) the weight loss rate, (C) the corresponding typical corrosion morphology, and (D) enlarged view of the corrosion surface.

composite. As shown in Figure 5B, the three-dimensional AFM images revealed that the surface roughness was only -0.145 to $0.212 \mu \mathrm{m}$ for the Fe part but enhanced to -5.5 to $3.8 \mu \mathrm{m}$ for the $\mathrm{Fe} / \mathrm{CaCl}_{2}$ composite. The curves detected on the $\mathrm{Fe} / \mathrm{CaCl}_{2}$ composite fluctuated in a larger range than those on the Fe part, as shown in Figure 5C, which also proved that the addition of $\mathrm{CaCl}_{2}$ brought about severe pitting corrosion and destroyed the matrix.

\section{Electrochemical Behavior}

The corrosion behavior of the $\mathrm{Fe}$ and $\mathrm{Fe} / \mathrm{CaCl}_{2}$ composites were further investigated by electrochemical tests. As shown in Figure 6A, the potentiodynamic polarization curves showed a typical anodic polarization behavior, resulting in the formation of the passivation film. After doping $\mathrm{CaCl}_{2}$, the breakdown potential of the passivation film was negatively shifted. The corrosion potential $\left(\mathrm{E}_{\text {corr }}\right)$ and corrosion current density $\left(\mathrm{i}_{\text {corr }}\right)$ were obtained by the Tafel region extrapolation method. $\mathrm{E}_{\text {corr }}$ was $-0.75 \pm 0.1 \mathrm{~V}$ for $\mathrm{Fe}$ and $-0.94 \pm 0.2 \mathrm{~V}$ for the $\mathrm{Fe} / \mathrm{CaCl}_{2}$ composite. However, the $\mathrm{i}_{\text {corr }}$ of the $\mathrm{Fe} / \mathrm{CaCl}_{2}$ composite was $31.4 \pm 0.9 \mu \mathrm{A} / \mathrm{cm}^{2}$, which was significantly enhanced as compared with that of $\mathrm{Fe}\left(11.1 \pm 0.4 \mu \mathrm{A} / \mathrm{cm}^{2}\right)$.

The EIS diagrams were obtained after immersion for 7,14 , and 28 days, as shown in Figure 6B. The impedance arcs for the Fe parts gradually increased with immersion time extending from 7 to 28 days, which were closely related with the formation of compact passive film during corrosion. However, the impedance arcs of the $\mathrm{Fe} / \mathrm{CaCl}_{2}$ composites immersed at 7,14 , and 28 days showed no obvious change and were significantly smaller than that of Fe. It was believed that the passive film was continuously selfdestroyed, thus reducing the protection efficiency. The structure of the passive film after immersing for 7,14 , and 28 days was analyzed using equivalent circuits fitted by the EIS spectra, as exhibited in Figure 6C. The circuit for the Fe part indicated the existence of one time constant. It represented a compact passive film which acted as a barrier against corrosion, wherein $R_{\mathrm{ct}}$ and $C_{\mathrm{d}}$ were the resistance and capacitance of the passive film, respectively. Distinctively, the circuit for $\mathrm{Fe} / \mathrm{CaCl}_{2}$ composites showed the existence of two-time constants, which indicated the formation of a porous passive film. In this model, the second time constant was charge transfer reaction, which could be illustrated by the double-layer capacitance $C_{\mathrm{d}}$ and charge transfer resistance $R_{\mathrm{ct}}$. The corresponding parameters obtained by fitting the EIS data are shown in Table 1. Obviously, $R_{\mathrm{ct}}$ increased with immersion time extending for the Fe part, which further proved the high resistance of the product layer and resultant protection efficiency. Meanwhile, its slight increase of $C_{\mathrm{d}}$ represented a growth of the compact passive film with a long-term stability. As for the Fe/ $\mathrm{CaCl}_{2}$ composite, a relatively low $R_{\mathrm{ct}}$ and $C_{\mathrm{d}}$ indicated its high charge transfer ability and porous product layer with poor protection efficiency (Marinenko and Foley, 1975; Darowicki and Gawel, 2017).

\section{In Vitro Cell Behavior}

The biocompatibility of the $\mathrm{Fe} / \mathrm{CaCl}_{2}$ composite was investigated, with $\mathrm{Fe}$ as control. In general, the cells gradually increased with culture time increasing to 5 days, as shown in Figure 7A. In terms of cell morphology, a large number of cells developed pseudopodia and 


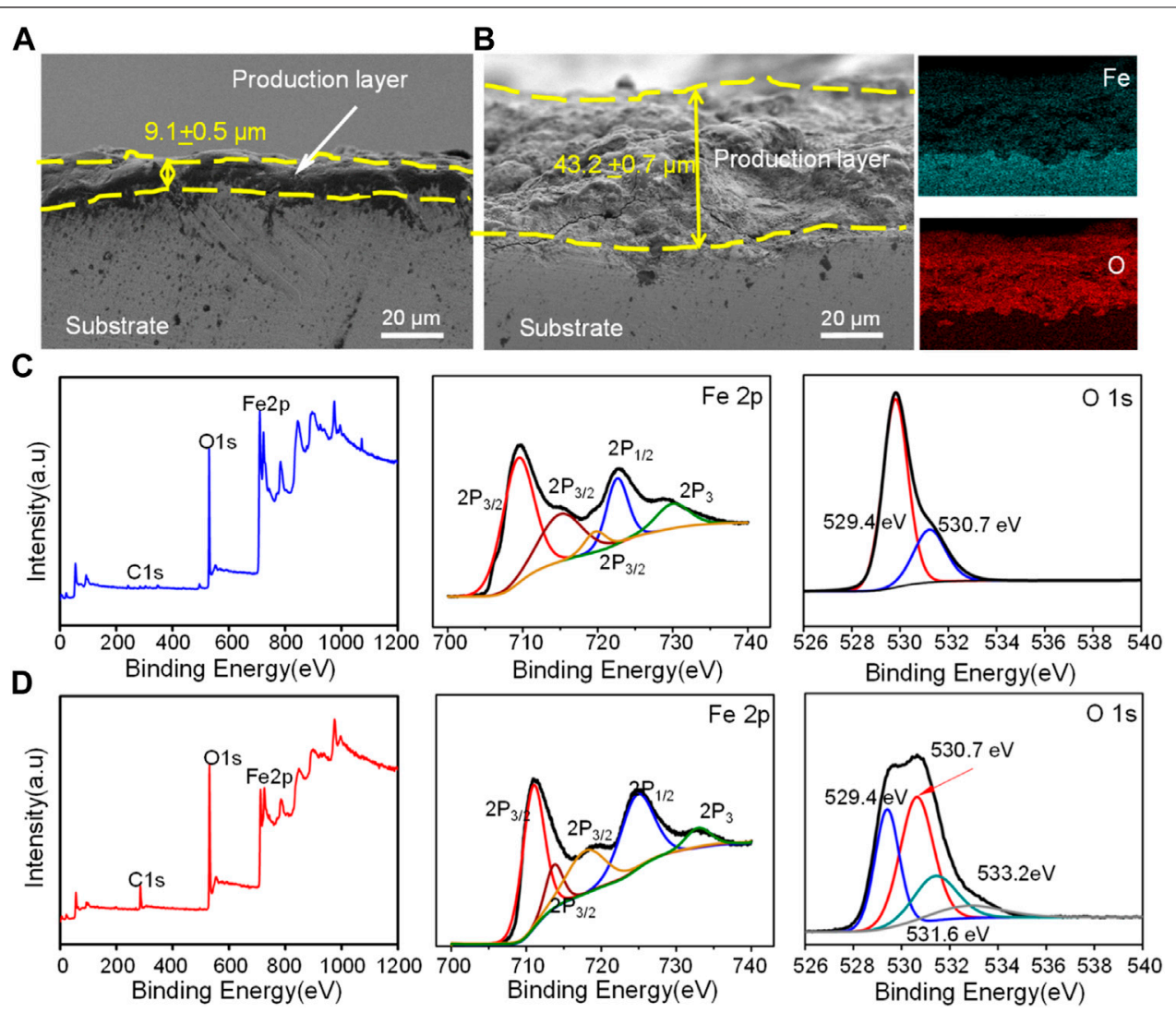

FIGURE 4 | The cross section of corrosion production for (A) Fe and (B) Fe/ $\mathrm{CaCl}_{2}$ after immersing for 28 days observed by SEM, and XPS analysis of the oxide layer for (C) Fe and (D) $\mathrm{Fe} / \mathrm{CaCl}_{2}$, wherein the sputtering time was $10 \mathrm{~s}$.

extracellular matrix at day 5. It was indicated that both the $\mathrm{Fe} / \mathrm{CaCl}_{2}$ composite and $\mathrm{Fe}$ exerted no obvious negative effect on cell growth. Furthermore, the cell survival rate was quantitatively analyzed by CCK-8 assay using 100\% concentration extracts, as shown in Figure 7B. In both two groups, the cell viabilities were greater than $75 \%$. According to ISO 10993-5-2009, the cytotoxicity was defined as grade 1 , which was acceptable for bone implants (ISO, 2009). Notably, the cell viability of the $\mathrm{Fe} / \mathrm{CaCl}_{2}$ composite group was slightly higher than that of the Fe group. As shown in Figure 7C, the cells cultured in the $\mathrm{Fe} / \mathrm{CaCl}_{2}$ group showed intensive ALP staining as compared with the Fe group after 7 days' culture, which revealed the improvement of cell differentiation behavior. It was believed that the released $\mathrm{Ca}$ ion, as one of the important components for the human body, might exert a positive effect on cell growth and differentiation.

\section{DISCUSSION}

Bone substitute was highly demanded aiming to achieve the tissue regeneration and functional reconstruction at critical defect sites (Puleo and Nanci, 1999; Li et al., 2020; Gao et al., 2021b; Qian et al., 2021). In the present study, Fe-based biocomposites were fabricated by laser additive manufacturing. Owing to the unique layer-by-layer fashion, it easily realized the preparation of implant with high geometric complexity and interconnected microporous structure, as well as the customized shape for different patients or defect sites (An and Draughn, 1999). The typical Fe-based scaffolds fabricated by LPBF are presented in Figure 8. Bone tissue engineering scaffolds with different porous structures could be customized according to different needs. The other significant feature of LPBF was its rapid solidification process, which was able to tailor the microstructure (Yang et al., 2020b). Under the effect of laser irradiation, Marangoni convection was generally formed within molten pool, which effectively promoted the rearrangement of reinforcing particles (Kruth et al., 2005; Feng et al., 2021). Subsequently, the molten pool experienced a rapid solidification, namely, the fast-advancing solid-liquid interface, which could refine the grains and promote the uniform dispersion of reinforcing particles by "capture effect," as shown in Figure 2.

Bone implants also needed to have a degradation rate that matched the bone growth rate, so as to provide space for new bone tissue growth (Trisi et al., 2002). As previous research reported, Fe bone implants degraded too slowly, owing to its high corrosion potential and compact passive film (Cha et al., 2015). In general, a high corrosion potential represented a low corrosion tendency, whereas the compact 


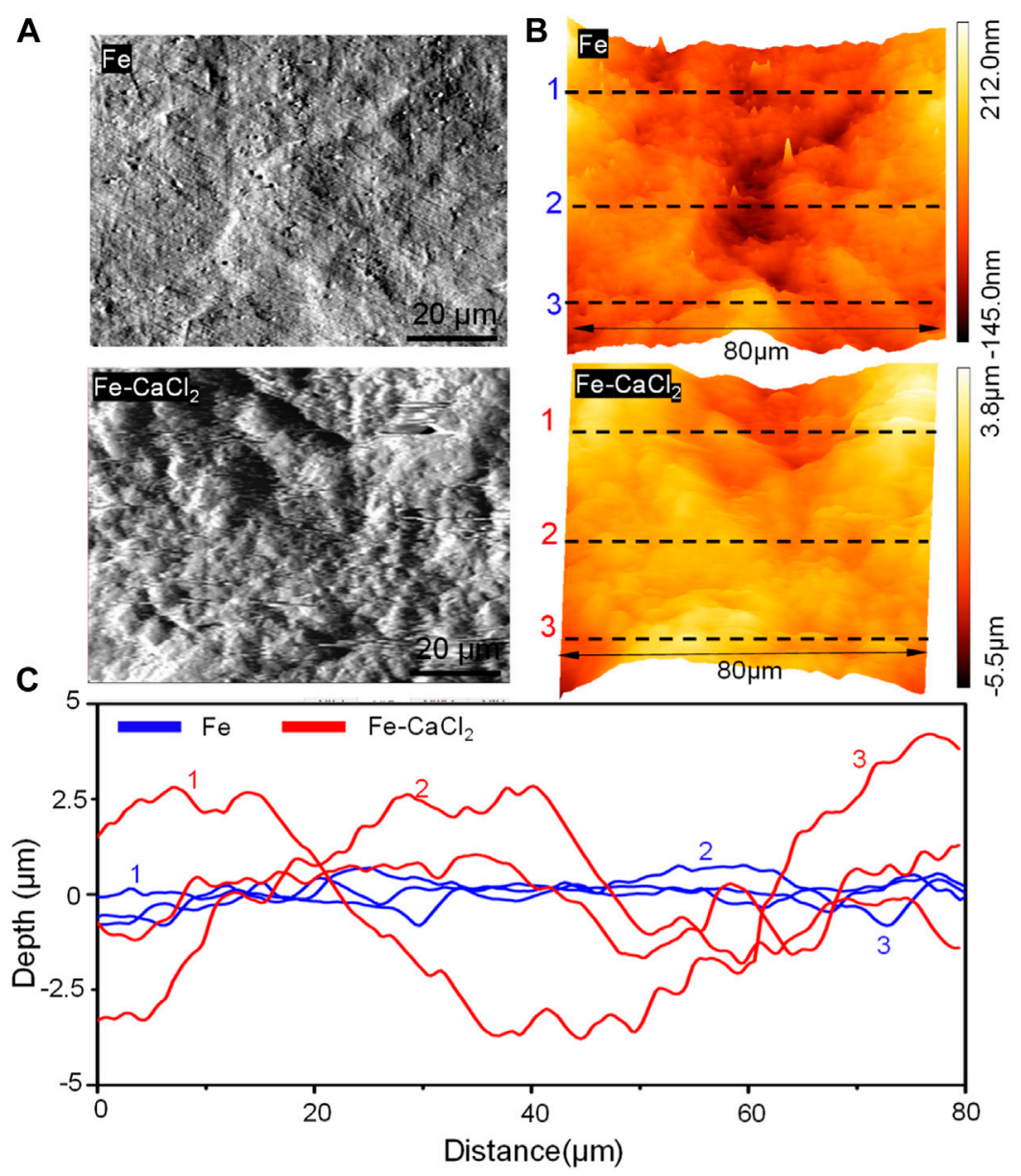

FIGURE 5 | (A) The AFM topography of the part surface in SBF for 28 days at $37^{\circ} \mathrm{C}$, (B) AFM three-dimensional images, and (C) the derived surface roughness profiles.

passive film acted as a barrier that seriously hindered the matrix erosion (Sato and Kudo, 1971). In the present study, $\mathrm{CaCl}_{2}$ as a halide was added into $\mathrm{Fe}$ bone implants and successfully accelerated the degradation, which was clearly proved by our immersion tests and electrochemical experiments. As shown in Figure 4, massive corrosion products with loose structure covered on the $\mathrm{Fe} / \mathrm{CaCl}_{2}$ composite. It was believed that the $\mathrm{Cl}$ ion released from the matrix resulted in the self-breakdown of the passivation film. In fact, $\mathrm{Cl}$ ion possessed strong electronegativity and could attach at the interface between the substrate and the passive film, thereby causing lattice expansion (Zhang et al., 2018). In this case, tensile stress was generally formed at the interface. Under this condition, the passive film located in the convex area of the interface was easily ruptured, thus forming micropores (Gao et al., 2021b). Herein, the Pilling-Bedworth ratio (PBR), defined as the ratio of the volume of oxide $\left(V_{o x}\right)$ and volume of metal $\left(V_{m}\right)$, was calculated to study the stress state of oxide film. According to the theory of PBR, the perfection or compactness of the oxide film could be expressed by (Zhou et al., 2010):

$$
\mathrm{PBR}=\frac{V_{o x}}{V_{m}}=\frac{m_{o x} \cdot \rho_{m}}{n \cdot A \cdot \rho_{o x}}
$$

where $m_{o x}, \rho_{m}$, and $\rho_{o x}$ are the molar weight of the oxide, metal, and oxide densities, respectively. $A$ and $n$ are the atomic weight of the metal and the number of metal atoms in the oxide molecules, respectively. Based on XPS fitting curve analysis (Figures 3B,C), the calculated PBR for the Fe/ $\mathrm{CaCl}_{2}$ composite had a relatively small value of about 0.93 as compared with Fe (1.92) by using Eq. 1. It was reported that $\mathrm{PBR}<1$ indicated a discontinuous and porous film with poor protection performance on the matrix ( $\mathrm{Xu}$ and Gao, 2000; Wang et al., 2019), since it contributed to a smooth way for $\mathrm{H}_{2} \mathrm{O}$ and ions to penetrate into the oxide film. Furthermore, the uncovered Fe matrix would act as anode, whereas the porous passivation film served as cathode of corrosion battery, thus further accelerating the anodic reaction (ElLateef et al., 2020).

On the other hand, our electrochemical experiments also proved that $\mathrm{CaCl}_{2}$ reduced the corrosion resistance by means of enhancing the charge transfer ability. Usually, the charge 

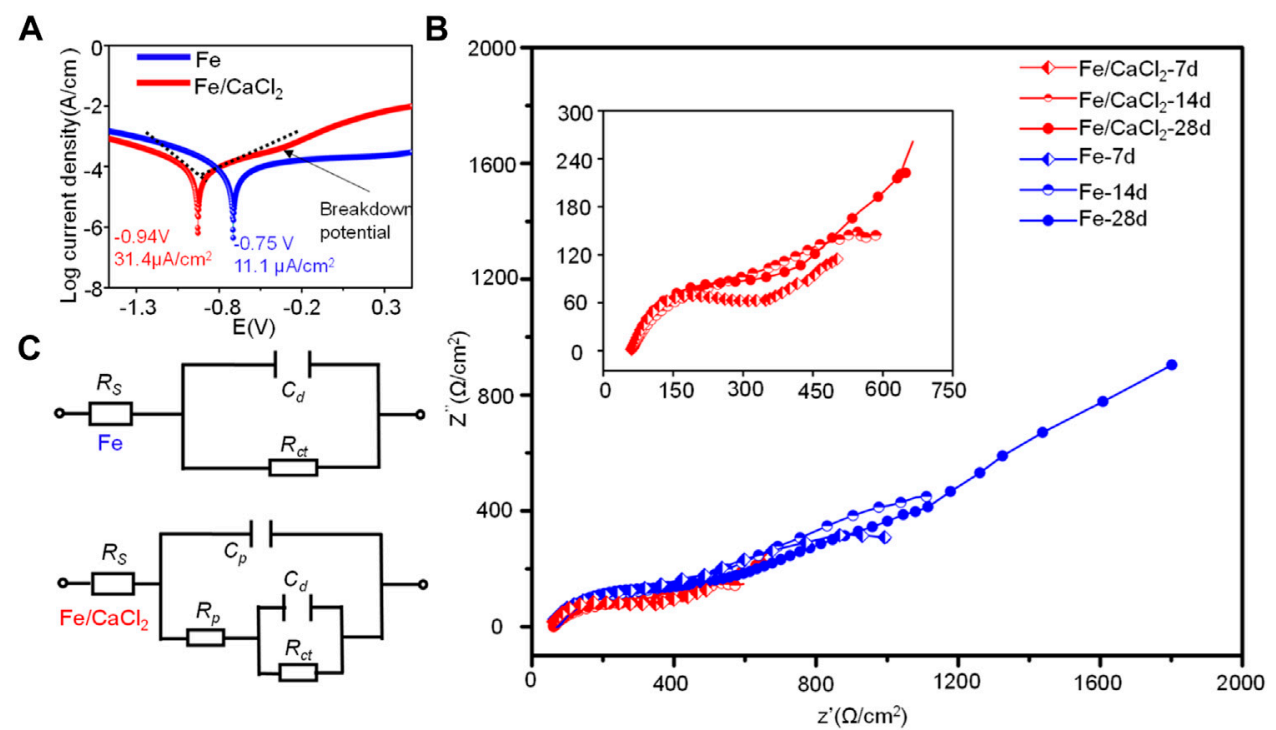

FIGURE 6 | (A) Tafel polarization curves for the Fe and Fe/CaCl 2 composites, (B) EIS diagrams, and (C) corresponding equivalent circuits after immersing for 7,14 , and 28 days.

TABLE 1 | Fitted parameters of EIS data for $\mathrm{Fe} / \mathrm{CaCl}_{2}$ composite and Fe.

\begin{tabular}{|c|c|c|c|c|c|c|}
\hline \multirow[t]{2}{*}{ Samples } & \multicolumn{3}{|c|}{$\mathrm{Fe}$} & \multicolumn{3}{|c|}{$\mathrm{Fe} / \mathrm{CaCl}_{2}$} \\
\hline & 7 days & 14 days & 28 days & 7 days & 14 days & 28 days \\
\hline$R_{\mathrm{ct}}\left(\Omega / \mathrm{cm}^{2}\right)$ & 996.3 & $1,097.8$ & $1,863.2$ & 81.19 & 103.21 & 145.34 \\
\hline$C_{d}(\mu F) \cdot 10^{-5}$ & 2.13 & 2.31 & 3.45 & 1.53 & 1.82 & 2.01 \\
\hline
\end{tabular}

transfer ability was closely related to the structure of the passive film (Liu et al., 2020; Palaniappan et al., 2017). As shown in Figures $\mathbf{9 A , B}$, the typical current density-time in linear and double logarithmic coordinate plots were polarized respectively at the film formation potential of $0.2 \mathrm{~V}$. In the transient, the current density represented the total current resulting from the passive film formation and dissolution in SBF (Kim et al., 2018). As shown in Figure 9A, the initial current density decreased sharply with time extending. It was because the growth of the passive film was relatively fast as compared with the dissolution process (Heo et al., 2016). Subsequently, the current density maintained stably, indicating a balance of the formation and dissolution of the passive film. It was worth noting that the current density for the $\mathrm{Fe} / \mathrm{CaCl}_{2}$ composite was relatively high as compared with $\mathrm{Fe}$, which corresponded to a weak protection ability of the passive film. Besides, the relatively high level of the current density gradually increased with time extending, which was attributed to the formation of the porous passive film (Lopes et al., 2019). As shown in Figure 9B, the decay rate for the $\mathrm{Fe} / \mathrm{CaCl}_{2}$ composite was much slow as compared with that of $\mathrm{Fe}$, which further confirmed that the porous passive film improved the charge transfer capability (Bernède et al., 2008).

The electronic property of the passive film was further characterized by in situ Mott-Schottky analysis. As shown in Figure 9C, the curve for the $\mathrm{Fe} / \mathrm{CaCl}_{2}$ composite exhibited a linear region with a positive slope in some potential range, which could be explained in detail by the capacitance of the passive film. According to the Mott-Schottky theory (Taveira et al., 2010), the capacitance $\left(C_{s c}\right)$ of passive film could be given by:

$$
C_{s c}^{-2}=\frac{2}{\varepsilon \varepsilon_{0} e N_{d}}\left(E-E_{d}-\frac{K T}{e}\right)
$$

where $\varepsilon$ and $N_{d}$ are the dielectric constant and donor density of the passive film, respectively. $e, E$, and $E_{d}$ correspond to the electric charge, the potential difference, and the potential in the flat band, respectively. $K, \varepsilon_{0}$, and $T$ represent the Boltzmann constant $\left(1.38 \times 10^{-23} \mathrm{~J} / \mathrm{K}\right)$, the vacuum dielectric constant $\left(8.854 \times 10^{-12} \mathrm{~F} / \mathrm{m}\right)$, and the thermodynamic temperature in kelvin, respectively. According to Eq. 2, the donor concentration of the passive film increased with the increase in potential difference, as shown in Figure 9D. It was attributed that the movement of oxide anions increased the donor density of the whole corrosion process as passivation started (Windisch et al., 2000). In fact, the high donor density could enhance the sensitivity of the passive film to $\mathrm{Cl}$ ion corrosion, which accelerated the penetration and transport of $\mathrm{Cl}$ ions to the passive film, thereby resulting in the rapid formation of the porous passive film. In this case, the protective ability of the passive film gradually decreased, which further promoted the destruction of passive film and the corrosion of the Fe matrix (Liu and Wu, 2007; Gerling et al., 2017).

Apart from the suitable porous structure, sufficient mechanical strength, and suitable mechanical properties, bone implants also need to provide a suitable microenvironment for the growth of new tissues (Pooja et al., 2014; Li et al., 2019; Narayanan et al., 2020; Qi et al., 

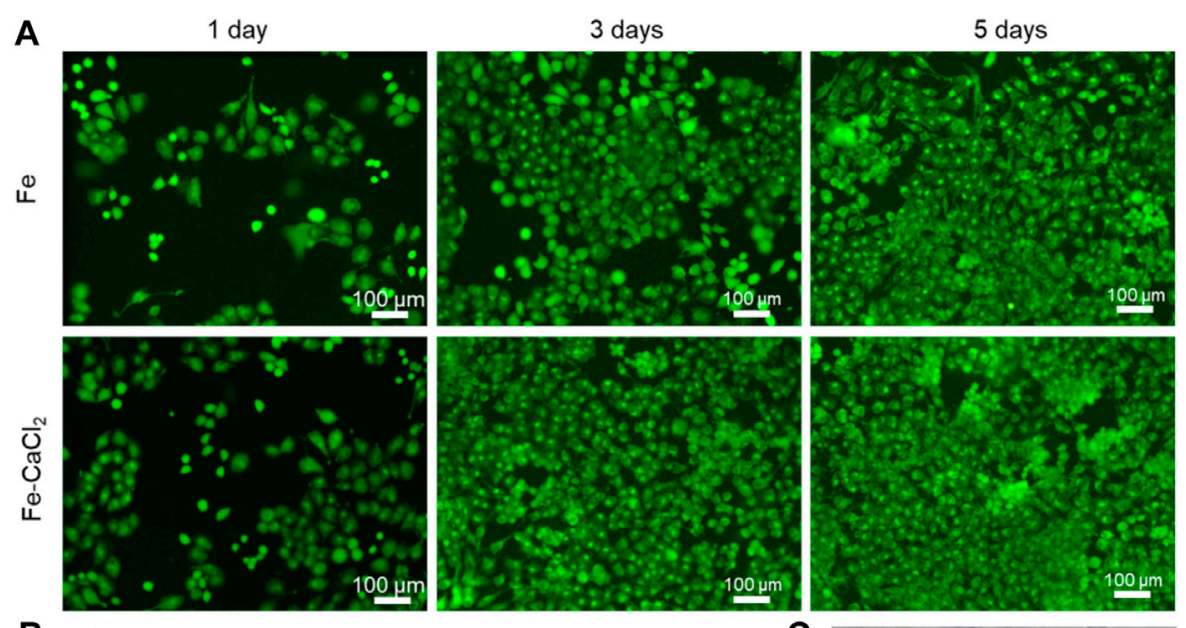

B
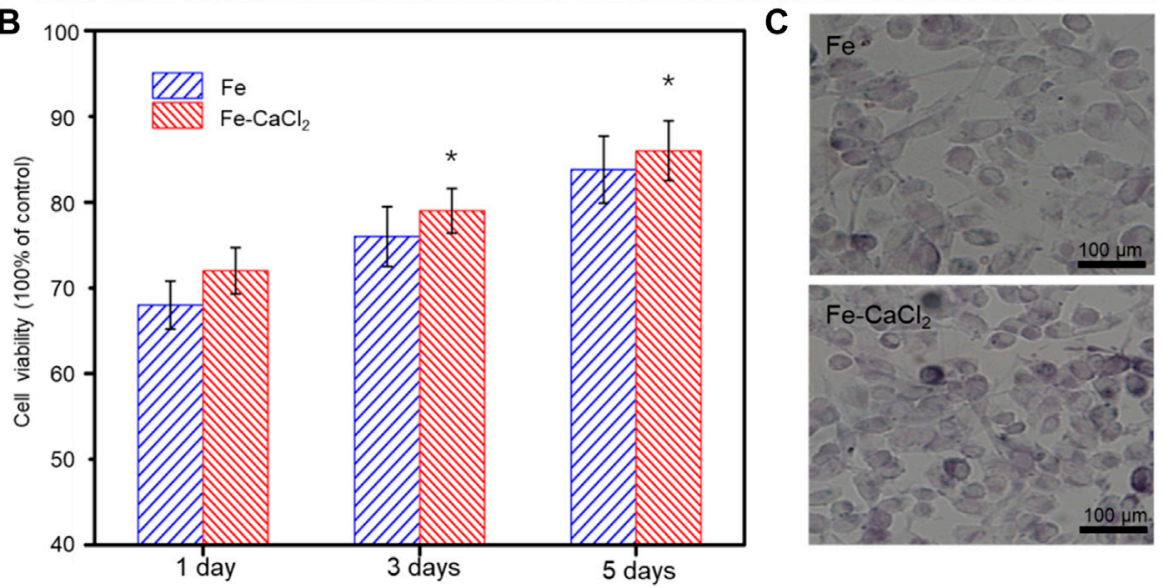

FIGURE 7 | (A) The cell fluorescent images after culture for 1, 3, and 5 days, and (B) the corresponding 100\% concentration extracts using CCK-8 assay. (C) ALP stained cell after culture for 7 days.

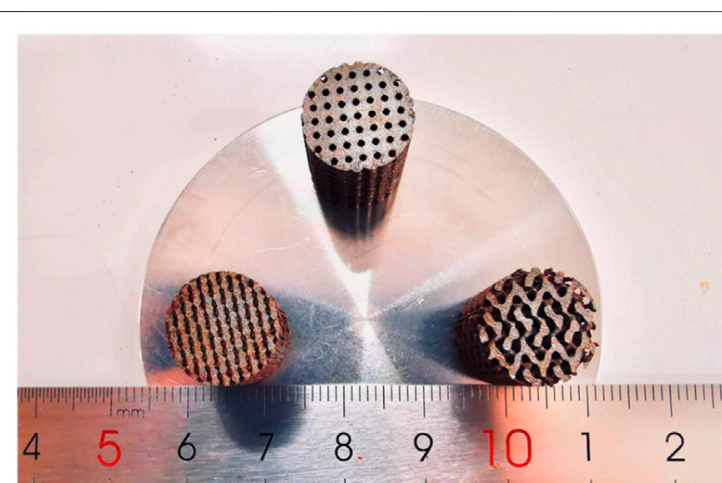

FIGURE 8 | Laser additively manufactured Fe-based scaffolds with porous structure.

2021). In the present study, the $\mathrm{Fe} / \mathrm{CaCl}_{2}$ biocomposite easily formed crystalline hydrate with water molecules, thereby showing a significant improvement of wettability, as shown in Figure 2C. Generally, the implants with favorable wettability could quickly promote the adsorption of proteins in body fluids (Russell, 2000; He et al., 2020). As a result, numerous functional groups on proteins were able to bind to cell surface receptors, thus enhancing cell adhesion behavior. Besides, the released $\mathrm{Ca}^{2+}$ ion from the $\mathrm{Fe} / \mathrm{CaCl}_{2}$ biocomposite promoted the cell growth, proliferation, and differentiation, as shown in Figure 7. For degradable implants, bone tissue was able to grow continuously during the process of dynamic degradation, so as to complete the repair of defect tissue and finally realize functional reconstruction (Zhao et al., 2015; He et al., 2021).

\section{CONCLUSION}

In this study, the $\mathrm{Fe} / \mathrm{CaCl}_{2}$ biocomposite was fabricated by laser additively manufacturing. The effects of $\mathrm{CaCl}_{2}$ on the microstructure, degradation behavior, and in vitro cell behavior were investigated. The conclusions were drawn as follows:

1) As compared with $\mathrm{Fe}$, the surface roughness of the $\mathrm{Fe} / \mathrm{CaCl}_{2}$ composite increased to -5.5 to $3.8 \mu \mathrm{m}$ after immersion for 28 days. The surface film presented massive porous, and its thickness increased to $43.2 \mu \mathrm{m}$. 

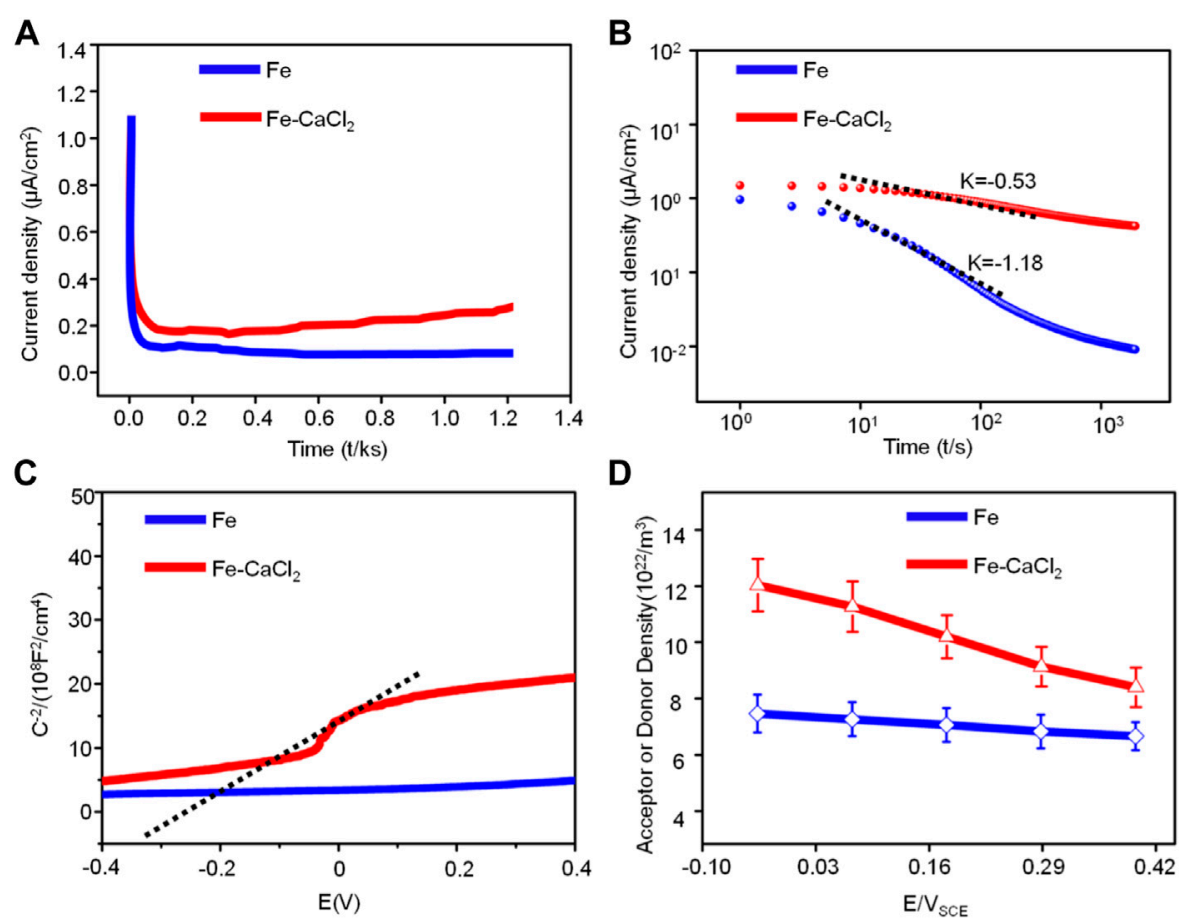

FIGURE 9 | (A) The current density-time in linear and (B) double logarithmic coordinates plots; (C) Mott-Schottky curves of Fe and Fe/CaCl 2 composite in SBF and (D) values of donor density.

2) The introduction of $\mathrm{CaCl}_{2}$ led to the negative shift of breakdown potential for Fe-based implants and the increase in corrosion current to $31.4 \pm 0.9 \mu \mathrm{A} / \mathrm{cm}^{2}$. Besides, the current density and donor concentration of the passive film gradually increased with time, thus resulting in the enhancement of conductivity.

3) The uniformly distributed $\mathrm{CaCl}_{2}$ decreased the water contacts of Fe-based bone implants to $55.2 \pm 1.2^{\circ}$, which improved the surface hydrophilicity and wettability. Meanwhile, $\mathrm{Fe} / \mathrm{CaCl}_{2}$ improved the cell growth and differentiation behavior, since the released $\mathrm{Ca}$ ion positively affected the cell response.

\section{DATA AVAILABILITY STATEMENT}

The raw data supporting the conclusions of this article will be made available by the authors, without undue reservation.

\section{REFERENCES}

An, Y. H., and Draughn, R. A. (1999). Mechanical Testing of Bone and the BoneImplant Interface. Boca Raton, Florida: CRC Press.

Bernède, J. C., Cattin, L., Morsli, M., Berredjem, Y., and Cells, S. (2008). Ultra-thin Metal Layer Passivation of the Transparent Conductive Anode in Organic Solar Cells. Solar Energ. Mater. Solar Cell 92 (11), 1508-1515. doi:10.1016/j.solmat.2008.06.016

\section{AUTHOR CONTRIBUTIONS}

Conceptualization, CS and YY; methodology, GC, MY; validation, CS, YY, and DW; formal analysis, SP; writing-review and editing, $\mathrm{YY}$ and $\mathrm{ZL}$.

\section{FUNDING}

This study was supported by the following funds: 1) National Natural Science Foundation of China (51935014, 52165043, 52105352, 82072084, 81871498); 2) JiangXi Provincial Natural Science Foundation of China (2020ACB214004, 20202BAB214011); 3) The Provincial Key R\&D Projects of Jiangxi (20201BBE51012); 4) The Project of State Key Laboratory of High Performance Complex Manufacturing; 5) China Postdoctoral Science Foundation (2020M682114); 6) Key Laboratory of Construction Hydraulic Robots of Anhui Higher Education Institutes, Tongling University (TLXYCHR-O-21YB01); and 7) Jiangsu Key Laboratory of Precision and Micro-Manufacturing Technology.

Cha, J. Y., Pereira, M. D., Smith, A. A., Houschyar, K. S., Yin, X., Mouraret, S., et al. (2015). Multiscale Analyses of the BoneImplant Interface. J. Dent Res. 94 (3), 482-490. doi:10.1177/ 0022034514566029

Chen, T., Shi, P., Zhang, J., Li, Y., Tian, X., Lian, J., et al. (2018). Bioinspired Enhancement of Chitosan Nanocomposite Films via Mg-ACC Crystallization, Their Robust, Hydrophobic and Biocompatible. Appl. Surf. Sci. 459, 129-137. doi:10.1016/j.apsusc.2018.07.194 
Chen, Z., Nong, Y., Chen, Y., Chen, J., and Yu, B. (2020). Study on the Adsorption of $\mathrm{OH}-$ and $\mathrm{CaOH}+$ on $\mathrm{Fe}(100)$ Surface and Their Effect on Passivation of Steel Bar: Experiments and DFT Modelling. Corrosion Sci. 174, 108804. doi:10.1016/j.corsci.2020.108804

Cheng, J., Liu, B., Wu, Y. H., and Zheng, Y. F. (2013). Comparative In Vitro Study on Pure Metals (Fe, Mn, Mg, Zn and W) as Biodegradable Metals. J. Mater. Sci. Tech. 29 (7), 619-627. doi:10.1016/j.jmst.2013.03.019

Darowicki, K., and Gawel, L. (2017). Impedance Measurement and Selection of Electrochemical Equivalent Circuit of a Working PEM Fuel Cell Cathode. Electrocatalysis 8 (3), 235-244. doi:10.1007/s12678-017-0363-0

El-Lateef, H. M. A., Albokheet, W. A., and Gouda, M. (2020). Carboxymethyl Cellulose/metal ( $\mathrm{Fe}, \mathrm{Cu}$ and $\mathrm{Ni}$ ) Nanocomposites as Non-precious Inhibitors of C-Steel Corrosion in $\mathrm{HCl}$ Solutions: Synthesis, Characterization, Electrochemical and Surface Morphology Studies. Cellulose 27 (14), 8039-8057. doi:10.1007/s10570-020-03292-6

Feng, P., Kong, Y., Liu, M., Peng, S., and Shuai, C. (2021). Dispersion Strategies for Low-Dimensional Nanomaterials and Their Application in Biopolymer Implants. Mater. Today Nano 15, 100127. doi:10.1016/j.mtnano.2021.100127

Gao, C., Yao, M., Peng, S., Tan, W., and Shuai, C. (2021a). Pre-oxidation Induced In Situ Interface Strengthening in Biodegradable $\mathrm{Zn} /$ nano-SiC Composites Prepared by Selective Laser Melting. J. Adv. Res.. doi:10.1016/j.jare.2021.09.014

Gao, C., Zeng, Z., Peng, S., and Shuai, C. (2021b). Magnetostrictive Alloys: Promising Materials for Biomedical Applications. Bioactive Materials.

Gerling, L. G., Voz, C., Alcubilla, R., and Puigdollers, J. (2017). Origin of Passivation in Hole-Selective Transition Metal Oxides for Crystalline Silicon Heterojunction Solar Cells. J. Mater. Res. 32 (2), 260-268. doi:10.1557/ jmr.2016.453

Gu, J.-L., Lu, S.-Y., Shao, Y., and Yao, K.-F. (2021). Segregating the Homogeneous Passive Film and Understanding the Passivation Mechanism of Ti-Based Metallic Glasses. Corrosion Sci. 178, 109078. doi:10.1016/j.corsci.2020.109078

He, F., Lu, T., Fang, X., Feng, S., Feng, S., Tian, Y., et al. (2020). Novel ExtrusionMicrodrilling Approach to Fabricate Calcium Phosphate-Based Bioceramic Scaffolds Enabling Fast Bone Regeneration. ACS Appl. Mater. Inter. 12 (29), 32340-32351. doi:10.1021/acsami.0c07304

He, F., Lu, T., Feng, S., Wang, Y., Huang, C., Zhang, Y., et al. (2021). Alliance of Gallium and Strontium Potently Mediates the Osteoclastic and Osteogenic Activities of $\beta$-tricalcium Phosphate Bioceramic Scaffolds. Chem. Eng. J. 412, 128709. doi:10.1016/j.cej.2021.128709

Heo, J. S., Jo, J.-W., Kang, J., Jeong, C.-Y., Jeong, H. Y., Kim, S. K., et al. (2016). Water-Mediated Photochemical Treatments for Low-Temperature Passivation of Metal-Oxide Thin-Film Transistors. ACS Appl. Mater. Inter. 8 (16), 10403-10412. doi:10.1021/acsami.5b12819

Hermawan, H., Purnama, A., Dube, D., Couet, J., and Mantovani, D. (2010). Fe-Mn Alloys for Metallic Biodegradable Stents: Degradation and Cell Viability Studies江. Acta Biomater. 6 (5), 1852-1860. doi:10.1016/j.actbio.2009.11.025

ISO (2009). Biological Evaluation of Medical Devices-Part 5: Tests for in Vitro Cytotoxicity. Switzerland: IOS, 10993-10995.-

Kim, J. Y., Kim, A.-Y., Liu, G., Woo, J.-Y., Kim, H., and Lee, J. K. (2018). Li4SiO4Based Artificial Passivation Thin Film for Improving Interfacial Stability of Li Metal Anodes. ACS Appl. Mater. Inter. 10 (10), 8692-8701. doi:10.1021/ acsami.7b18997

Kim, M., Kim, G.-H., Lee, T. K., Choi, I. W., Choi, H. W., Jo, Y., et al. (2019). Methylammonium Chloride Induces Intermediate Phase Stabilization for Efficient Perovskite Solar Cells. Joule 3 (9), 2179-2192. doi:10.1016/ j.joule.2019.06.014

Kong, D., Dong, C., Wei, X., Man, C., Lei, X., Mao, F., et al. (2018). Size Matching Effect between Anion Vacancies and Halide Ions in Passive Film Breakdown on Copper. Electrochimica Acta 292, 817-827. doi:10.1016/j.electacta.2018.10.004

Kruth, J. P., Mercelis, P., Van Vaerenbergh, J., Froyen, L., and Rombouts, M. J. R. P. J. (2005). Binding Mechanisms in Selective Laser Sintering and Selective Laser Melting.

Li, J., Liu, X., Crook, J. M., and Wallace, G. G. (2020). 3D Printing of Cytocompatible Graphene/alginate Scaffolds for Mimetic Tissue Constructs. Front. Bioeng. Biotechnol. 8, 824. doi:10.3389/fbioe.2020.00824

Li, L., Shi, J., Zhang, K., Yang, L., Yu, F., Zhu, L., et al. (2019). Early Osteointegration Evaluation of Porous Ti6Al4V Scaffolds Designed Based on Triply Periodic Minimal Surface Models. J. Orthopaedic Translation 19, 94-105. doi:10.1016/j.jot.2019.03.003
Li, Y., Jahr, H., Lietaert, K., Pavanram, P., Yilmaz, A., Fockaert, L. I., et al. (2018). Additively Manufactured Biodegradable Porous Iron. Acta Biomater. 77, 380-393. doi:10.1016/j.actbio.2018.07.011

Liu, C., and Wu, J. J. C. S. (2007). Influence of $\mathrm{pH}$ on the Passivation Behavior of 254SMO Stainless Steel in 3. 5\% NaCl Solution 49 (5), 2198-2209.

Liu, K., He, P., Bai, H., Chen, J., Dong, F., Wang, S., et al. (2017). Effects of Dodecyltrimethylammonium Bromide Surfactant on Both Corrosion and Passivation Behaviors of Zinc Electrodes in Alkaline Solution. Mater. Chem. Phys. 199, 73-78. doi:10.1016/j.matchemphys.2017.06.050

Liu, S., Fang, X., Lu, B., and Yan, D. (2020). Wide Range zero-thermal-quenching Ultralong Phosphorescence from Zero-Dimensional Metal Halide Hybrids. Nat. Commun. 11 (1), 4649-9. doi:10.1038/s41467-020-18482-w

Lopes, T. S., Cunha, J. M. V., Bose, S., Barbosa, J. R. S., Borme, J., Donzel-Gargand, O., et al. (2019). Rear Optical Reflection and Passivation Using a Nanopatterned Metal/dielectric Structure in Thin-Film Solar Cells. IEEE J. Photovoltaics 9 (5), 1421-1427. doi:10.1109/jphotov.2019.2922323

Marinenko, G., and Foley, R. T. (1975). Absolute Determination of the Electrochemical Equivalent and the Atomic Weight of Zinc. I. Method, Apparatus, and Preliminary Experiments. J. Res. Natl. Bur. Stan. Sect. A. 79A (6), 737. doi:10.6028/jres.079a.030

Narayanan, N., Jiang, C., Wang, C., Uzunalli, G., Whittern, N., Chen, D., et al. (2020). Harnessing Fiber Diameter-dependent Effects of Myoblasts toward Biomimetic Scaffold-Based Skeletal Muscle Regeneration. Front. Bioeng. Biotechnol. 8, 203. doi:10.3389/fbioe.2020.00203

Palaniappan, N., Chowhan, L. R., Jothi, S., Bosco, I. G., and Cole, I. S. (2017). Corrosion Inhibition on Mild Steel by Phosphonium Salts in 1 M HNO 3 Aqueous Medium. Surf. Inter. 6, 237-246. doi:10.1016/j.surfin.2016.10.003

Pérez-Ruiz, J. D., de Lacalle, L. N. L., Urbikain, G., Pereira, O., Martínez, S., and Bris, J. (2021). On the Relationship between Cutting Forces and Anisotropy Features in the Milling of LPBF Inconel 718 for Near Net Shape Parts. Int. J. Machine Tools Manufacture 170, 103801. doi:10.1016/ j.ijmachtools.2021.103801

Pooja, D., Panyaram, S., Kulhari, H., Rachamalla, S. S., and Sistla, R. (2014). Xanthan Gum Stabilized Gold Nanoparticles: Characterization, Biocompatibility, Stability and Cytotoxicity. Carbohydr. Polym. 110, 1-9. doi:10.1016/j.carbpol.2014.03.041

Puleo, D. A., and Nanci, A. (1999). Understanding and Controlling the BoneImplant Interface. Biomaterials 20 (23-24), 2311-2321. doi:10.1016/s01429612(99)00160-x

Qi, F., Zeng, Z., Yao, J., Cai, W., Zhao, Z., Peng, S., et al. (2021). Constructing CoreShell Structured BaTiO3@carbon Boosts Piezoelectric Activity and Cell Response of Polymer Scaffolds. Mater. Sci. Eng. C 126, 112129. doi:10.1016/ j.msec.2021.112129

Qian, G., Zhang, L., Wang, G., Zhao, Z., Peng, S., and Shuai, C. (2021). 3D Printed Zn-Doped Mesoporous Silica-Incorporated Poly-L-Lactic Acid Scaffolds for Bone Repair. Int. J. Bioprinting 7 (2). doi:10.18063/ijb.v7i2.346

Russell, J. M. (2000). Sodium-potassium-chloride Cotransport. Physiol. Rev. 80, 211-276.

Sato, N., and Kudo, K. (1971). Ellipsometry of the Passivation Film on Iron in Neutral Solution. Electrochimica Acta 16 (4), 447-462. doi:10.1016/00134686(71)85182-4

Seol, Y. J., Park, J. Y., Jung, J. W., Jang, J., Girdhari, R., Kim, S. W., et al. (2014). Improvement of Bone Regeneration Capability of Ceramic Scaffolds by Accelerated Release of Their Calcium Ions. Tissue Eng. Part. A. 20 (21-22), 2840-2849. doi:10.1089/ten.TEA.2012.0726

Sharma, P., and Pandey, P. M. (2019). Corrosion Behaviour of the Porous Iron Scaffold in Simulated Body Fluid for Biodegradable Implant Application. Mater. Sci. Eng. C 99, 838-852. doi:10.1016/j.msec.2019.01.114

Shuai, C., He, C., Peng, S., Qi, F., Wang, G., Min, A., et al. (2021). Mechanical Alloying of Immiscible Metallic Systems: Process, Microstructure, and Mechanism. Adv. Eng. Mater. 23, 2001098. doi:10.1002/adem.202001098

Shuai, C., He, C., Peng, S., Qi, F., Wang, G., Min, A., et al. (2021). Mechanical Alloying of Immiscible Metallic Systems: Process, Microstructure, and Mechanism. Adv. Eng. Mater. 23 (4), 2001098. doi:10.1002/ adem.202001098

Spotorno, R., Ghiara, G., Latronico, G., Carlini, R., Mele, P., and Artini, C. J. J. O. E. M. (2020). Corrosion of the Filled Skutterudite Sm 0.1 (Fe 0.45 Ni 0.55) 4 Sb 12 by $\mathrm{NaCl}$ Solutions. Electrochem. Study, 1-9. 
Taveira, L. V., Montemor, M. F., Da Cunha Belo, M., Ferreira, M. G., and Dick, L. F. P. (2010). Influence of Incorporated $\mathrm{Mo}$ and $\mathrm{Nb}$ on the Mott-Schottky Behaviour of Anodic Films Formed on AISI 304L. Corrosion Sci. 52 (9), 2813-2818. doi:10.1016/j.corsci.2010.04.021

Trisi, P., Lazzara, R., Rao, W., Rebaudi, A. J. I. J. o. P., and Dentistry, R. (2002). Bone-implant Contact and Bone Quality: Evaluation of Expected and Actual Bone Contact on Machined and Osseotite Implant Surfaces, 22.6.

Wang, D., Deng, G.-w., Yang, Y.-q., Chen, J., Wu, W.-h., Wang, H.-l., et al. (2021). Interface Microstructure and Mechanical Properties of Selective Laser Melted Multilayer Functionally Graded Materials. J. Cent. South. Univ. 28 (4), 1155-1169. doi:10.1007/s11771-021-4687-9

Wang, H., Yu, W., and Shen, S. (2019). Chemo-mechanical Coupling Effect in the High-Temperature Oxidation of Metal Materials: A Review. Sci. China Technol. Sci. 62 (8), 1246-1254. doi:10.1007/s11431-018-9500-y

Wang, L., Dou, Y., Han, S., Wu, J., and Cui, Z. (2020). Influence of Sulfide on the Passivation Behavior and Surface Chemistry of 2507 Super Duplex Stainless Steel in Acidified Artificial Seawater. Appl. Surf. Sci. 504, 144340. doi:10.1016/ j.apsusc.2019.144340

Wang, Z. B., Hu, H. X., Liu, C. B., and Zheng, Y. G. (2014). The Effect of Fluoride Ions on the Corrosion Behavior of Pure Titanium in $0.05 \mathrm{M}$ Sulfuric Acid. Electrochimica Acta 135, 526-535. doi:10.1016/j.electacta.2014.05.055

Windisch, C. F., Jr, Exarhos, G. J., and Technology A, S. (2000). Mott-schottky Analysis of Thin ZnO Films. J. Vacuum Sci. Tech. A: Vacuum, Surf. Films 18 (4), 1677-1680. doi:10.1116/1.582406

Wu, P., Zhu, X., Xu, L., Peng, W., and Zhao, G. (2020). Effect of Stray Current Coupled with Chloride Concentration and Temperature on the Corrosion Resistance of a Steel Passivation Film. Electrochemistry Commun. 118, 106793. doi:10.1016/j.elecom.2020.106793

$\mathrm{Xu}, \mathrm{C}$, and Gao, W. (2000). Pilling-Bedworth Ratio for Oxidation of Alloys. Mater. Res. Innov. 3 (4), 231-235. doi:10.1007/s100190050008

Yang, C., Huan, Z., Wang, X., Wu, C., and Chang, J. (2018). 3D Printed Fe Scaffolds with HA Nanocoating for Bone Regeneration. ACS Biomater. Sci. Eng. 4 (2), 608-616. doi:10.1021/acsbiomaterials.7b00885

Yang, H., Jia, B., Zhang, Z., Qu, X., Li, G., Lin, W., et al. (2020). Alloying Des. biodegradable zinc as promising bone Implants load-bearing Appl. 11 (1), 1-16. doi:10.1038/s41467-019-14153-7

Yang, Y., He, C., Dianyu E, E., Yang, W., Qi, F., Xie, D., et al. (2020). Design, Mg Bone Implant: Features, Developments and Perspectives. Mater. Des. 185, 108259. doi:10.1016/j.matdes.2019.108259
Yang, Y., Lu, C., Shen, L., Zhao, Z., Peng, S., and Shuai, C. (2021). In-situ Deposition of Apatite Layer to Protect Mg-Based Composite Fabricated via Laser Additive Manufacturing. J. Magnesium Alloys. doi:10.1016/ j.jma.2021.04.009

Yin, X., Wang, H., Sun, S., and Han, E.-H. (2020). Comparative Study on the Adsorption Behaviors of $\mathrm{O}$ and $\mathrm{Cl}$ on $\mathrm{Fe}(110)$ Surfaces with Different $\mathrm{Cr}$ Content. Mater. Today Commun. 24, 101122. doi:10.1016/ j.mtcomm.2020.101122

Zhang, B., Wang, J., Wu, B., Guo, X. W., Wang, Y. J., Chen, D., et al. (2018). Unmasking Chloride Attack on the Passive Film of Metals. Nat. Commun. 9 (1), 2559-9. doi:10.1038/s41467-018-04942-x

Zhao, J., Lai, H., Lyu, Z., Jiang, Y., Xie, K., Wang, X., et al. (2015). Hydrophilic Hierarchical Nitrogen-Doped Carbon Nanocages for Ultrahigh Supercapacitive Performance. Adv. Mater. 27 (23), 3541-3545. doi:10.1002/adma.201500945

Zhou, H., Qu, J., and Cherkaoui, M. (2010). Stress-oxidation Interaction in Selective Oxidation of Cr-Fe Alloys. Mech. Mater. 42 (1), 63-71. doi:10.1016/j.mechmat.2009.09.007

Zhou, S., Yan, Q., Tang, C., Mao, F., Pu, J., and Macdonald, D. D. (2020). Effect of the Chloride on Passivity Breakdown of Al-Zn-Mg alloy. Corrosion Sci. 163, 108254. doi:10.1016/j.corsci.2019.108254

Conflict of Interest: The authors declare that the research was conducted in the absence of any commercial or financial relationships that could be construed as a potential conflict of interest.

Publisher's Note: All claims expressed in this article are solely those of the authors and do not necessarily represent those of their affiliated organizations, or those of the publisher, the editors, and the reviewers. Any product that may be evaluated in this article, or claim that may be made by its manufacturer, is not guaranteed or endorsed by the publisher.

Copyright (c) 2021 Yang, Cai, Yang, Wang, Peng, Liu and Shuai. This is an openaccess article distributed under the terms of the Creative Commons Attribution License (CC BY). The use, distribution or reproduction in other forums is permitted, provided the original author(s) and the copyright owner(s) are credited and that the original publication in this journal is cited, in accordance with accepted academic practice. No use, distribution or reproduction is permitted which does not comply with these terms. 